\title{
Exploring User Experience on Mobile Library Service by Cognitive Mapping
}

\author{
Yaming $\mathrm{Fu}$ \\ Department of Information Studies \\ University College London \\ London, United Kingdom \\ yaming.fu.17@ucl.ac.uk
}

\begin{abstract}
The ubiquitous application of mobile web technology is having a significant impact on education and is changing the way of learning and teaching. With this evolving technological change, new ways of exploring information behaviour and user experience with mobile devices are needed.

This research aims to explore user experience (UX) by using an innovative ethnographic approach, cognitive mapping, trying to investigate this issue from an interpretivist viewpoint. A triangulation of log analysis, cognitive mapping and semi-structured interview is adopted to gain a comprehensive view of how users interact with mobile technology with a specific look into their experience on using the mobile library service.
\end{abstract}

\section{KEYWORDS}

User experience; Information behaviour; Cognitive mapping; Mobile library service

\section{ACM Reference Format:}

Yaming Fu. 2019. Exploring User Experience on Mobile Library Service by Cognitive Mapping. In 2019 Conference on Human Information Interaction and Retrieval (CHIIR '19), March 10-14, 2019, Glasgow, United Kingdom. ACM, New York, NY, USA, 4 pages. https://doi.org/10.1145/3295750.3298968

\section{INTRODUCTION AND MOTIVATION}

Technology advancement always has a great impact on the way of teaching and learning, bringing revolutionary changes to education world [18]. Mobile web technology, from its advent, brought new possibilities in the way of accessing, seeking, using and sharing information and this also brought changes to the way library promoting their resources and services. The concept "mobile library service" was raised up with the mobile web technology development, meaning the online library service that can be accessed via mobile devices [21]. Previous research around the topic of mobile library service focused on assessing users' acceptance on using mobile devices to work by adopting theoretical frameworks like Technology Acceptance Model (e.g: [2]) or on the implementation and construction of certain mobile service (e.g: $[9,14])$. While it has been indicated that the way people use their mobile devices is

Permission to make digital or hard copies of part or all of this work for personal or classroom use is granted without fee provided that copies are not made or distributed for profit or commercial advantage and that copies bear this notice and the full citation on the first page. Copyrights for third-party components of this work must be honored

For all other uses, contact the owner/author(s).

CHIIR '19, March 10-14, 2019, Glasgow, United Kingdom

(c) 2019 Copyright held by the owner/author(s).

ACM ISBN 978-1-4503-6025-8/19/03.

https://doi.org/10.1145/3295750.3298968 shifting from merely communicating to exploring, reading, sharing and learning, as well as producing digital contents [8]. In the mobile environment, the user's context is dynamic. There are constant changes in the characteristics of users at different times, different locations, facing different tasks with a specific demand. The changing information behaviour with mobile technology and their user experience should be looked into in order to understand the users in the mobile age. Therefore, this research is aiming to fill the gap to look into how users' information behaviour changes with the mobile devices, what is their experience on such technological shift in the library context and what are their expectations on the future mobile library service development.

In the library context, UX is not a new area of study. Most of the library UX study focus on improving the effectiveness of library website interface and task design to meet users' search goals and perform a better task on the library websites [5]. When Don Norman, the pioneer of UX research, published his work 'Living with Complexity' in 2011, a complexity nature of design and user experience was uncovered [20]. UX in the library is more than just the usability of web-based services, but should be a comprehensive and systemic concept in all aspects of library service design. Therefore, rather than only focusing on the library system, some of the libraries started to adopt ethnographic techniques to learn about their users. Many of the early works on using ethnographic concepts in learning UX in the library context were from libraries in USA and Canada and their pioneer works led to more user-centered research in libraries that look beyond the system, and focus more on people [19]. In UK, ethnographic methods started gaining popularity in the late 2000s. In 2009, for example, the library of the University of Loughborough in UK conducted an observational study to explore students' activities took place in library learning space [7].

It gives inspiration to this research to adopt an ethnographic technique, cognitive mapping, to investigate UX and look beyond the system, trying to explore a new way of understanding human information behavior and UX with technologies.

\section{RESEARCH QUESTIONS}

The goal of this research is to investigate information behaviours and user experiences in the context of mobile library services, in order to learn about library users in the mobile age and to better understand their changing habits triggered by technological shifts. The research engages libraries with a deeper understanding around explicit goals to update their mobile services. Therefore, the research questions are as follows: 
RQ1: What information behaviours and user experiences do individual evidence when using library service on their mobile devices?

RQ2: What do students do now and what would they like to be able to do in the future as technologies and possibilities evolve with mobile library service?

RQ3: How can the library improve its service with mobile technologies to better support students' mobile learning behavior?

\section{METHODOLOGIES}

This research adopts an interpretivist framework. The research explores subjective experience, seeking to understand the meanings of and reasons behind user behaviours. Qualitative data is the main resource of the research, aiming to discover the inner experience of people [10]. Meeting the research aim, a triangulation of methods, including log analysis, cognitive mapping and semi-structured interview is employed, which gives validation to the research outcomes [13].

\subsection{Cognitive Mapping}

Cognitive mapping is a method derived from geography and psychology research and it is used to get a visual representation of the way users utilise or think about a particular resource or place [17] The term "map" here does not refer to the 'pictorial graphic model', but means the process of forming the cognition of the outsider environment and the representation of such cognition Downs and Stea [11, p.313].

In the library context, cognitive mapping is known as one of the ways to get rich data in a short time. From the year 2000, this method started to be used in the context of academic libraries in studying the users' behaviour in the way they interact with the resources and services provided by physical or digital library $[3,12]$. One of its successful applications is from the ERIAL Project (Ethnographic Research in Illinois Academic Libraries), where 137 students from five ERIAL campuses engaged in the study and drew their impressions of the library.

To conduct cognitive mapping, participants are asked to draw their opinions on a piece of paper using three different color pens in six minutes given in total. They are required to change the color of the pen in every two minutes to show the sequence and relative importance of their mind map stages.

A follow-up interview is often used as a complementary method with cognitive mapping to allow participants to explain their drawings and discuss the topic in detail. Through labelling the elements appeared on the drawing and discovering the reason behind the scene, researchers will get in-depth and sometimes unexpected answers and perspectives from participants [22]

\subsection{Procedure}

This research was conducted in three stages. In the first stage of research, a pilot study was carried out on a small scale of sample in order to test the research methods and give inspirations to the next stages design of research, especially the design of the cognitive mapping session and the interview questions. In addition, the pilot study gave clues on the sample choice in the formal stage of research.
In the second stage of research, log analysis will be used to analyse the backend data from library regarding users' current behavioural data on mobile devices. This part of data will give an overview of the current information behaviour statistics (e.g: user actions, devices usage, popular searches, sessions, etc.).

The third stage of research will be to conduct cognitive mapping and semi-structured interviews. This part of research is mainly to find out the UX aspect on mobile library service, aiming to find out the reasons behind their information behaviour, the way how mobile service changed their behaviour and experience and their expectations of its future development.

\section{PROGRESS}

Through the first year of research, a comprehensive review on the literature around information behavior and UX was achieved. The first stage of this study, the pilot study, was carried out and initial data was obtained and analysed.

In the pilot study, a small sample of six students studying in University College London from different cultural and academic backgrounds were recruited. Each session combined with a cognitive mapping and an interview lasting around 30 minutes in a study room with one student and the researcher.

Six cognitive maps were gathered and by analyzing the elements appeared on maps, 67 unique elements were identified. These elements were then grouped by themes into five categories. Through analyzing interview transcriptions by content analysis, 180 quotes were coded and then categorized into seven categories.

The comparison between the number of elements/quotes in the categories of cognitive maps and interviews is shown in Table 1.

Table 1: The comparison between the number of elements/quotes in the categories of cognitive maps and interviews

\begin{tabular}{|l|l|l|l|}
\hline $\begin{array}{l}\text { Category in } \\
\text { maps }\end{array}$ & $\begin{array}{l}\text { Number } \\
\text { of ele- } \\
\text { ments }\end{array}$ & $\begin{array}{l}\text { Category in in- } \\
\text { terviews }\end{array}$ & $\begin{array}{l}\text { Number } \\
\text { of } \\
\text { quotes }\end{array}$ \\
\hline $\begin{array}{l}\text { Expectations } \\
\text { on mobile } \\
\text { library service }\end{array}$ & 18 & $\begin{array}{l}\text { Expectations } \\
\text { on mobile } \\
\text { library service }\end{array}$ & 52 \\
\hline $\begin{array}{l}\text { Mobile learning } \\
\text { behaviour }\end{array}$ & 9 & $\begin{array}{l}\text { Mobile learning } \\
\text { behaviour }\end{array}$ & 63 \\
\hline Library services & 15 & Library services & 16 \\
\hline $\begin{array}{l}\text { Library re- } \\
\text { sources }\end{array}$ & 10 & $\begin{array}{l}\text { Library re- } \\
\text { sources }\end{array}$ & 16 \\
\hline Others & 15 & $\begin{array}{l}\text { Opinions on } \\
\text { Cognitive } \\
\text { mapping }\end{array}$ & 15 \\
\hline & $\begin{array}{l}\text { Library cata- } \\
\text { logue usage }\end{array}$ & 12 \\
\hline & $\begin{array}{l}\text { Experience on } \\
\text { using library } \\
\text { apps }\end{array}$ & 6 \\
\hline
\end{tabular}

During cognitive map drawing, students were given three different color pens to show their sequence of thinking and drawing. 
Frequency/Position $(\mathrm{F} / \mathrm{P})$ index was created according to the frequency of the element and the position it appeared in the drawing (first, second or third). The index calculated in this way (frequency divided by the mean position of an element) can indicate the relative importance of each element [3]. The elements with the F/P index higher than 1 are shown in Table 2.

Table 2: Cognitive maps elements with F/P index higher than 1

\begin{tabular}{|c|c|c|c|}
\hline Element & Frequency & $\begin{array}{l}\text { Mean } \\
\text { Posi- } \\
\text { tion }\end{array}$ & $\begin{array}{l}\mathrm{F} / \mathrm{P} \text { in- } \\
\mathrm{dex}\end{array}$ \\
\hline \multicolumn{4}{|c|}{ Library Resources } \\
\hline $\begin{array}{l}\text { "Explore" Search (library } \\
\text { catalogue) }\end{array}$ & 7 & 1.14 & 6.14 \\
\hline $\begin{array}{l}\text { Books, articles, journals, } \\
\text { archives, newspapers }\end{array}$ & 6 & 1.16 & 5.17 \\
\hline Physical libraries & 3 & 1.33 & 2.26 \\
\hline Book status track & 5 & 2.4 & 2.08 \\
\hline $\begin{array}{l}\text { Database (web of science, } \\
\text { etc) }\end{array}$ & 2 & 1 & 2 \\
\hline \multicolumn{4}{|c|}{ Library services } \\
\hline User Log in & 5 & 2 & 2.5 \\
\hline Wifi, eduroam & \begin{tabular}{l|l}
3 & \\
\end{tabular} & 2 & 1.5 \\
\hline \multicolumn{4}{|c|}{ Expectations on mobile library service } \\
\hline Accessibility & \begin{tabular}{l|l}
5 \\
\end{tabular} & 2.2 & 2.27 \\
\hline University logo & 2 & 1 & 2 \\
\hline $\begin{array}{l}\text { Playability, desirability, } \\
\text { gamification }\end{array}$ & 3 & 2 & 1.5 \\
\hline $\begin{array}{l}\text { Information security (finger } \\
\text { print, face id) }\end{array}$ & 3 & 2.65 & 1.13 \\
\hline \multicolumn{4}{|c|}{ Mobile Learning behaviour } \\
\hline Location: on the move & \begin{tabular}{l|l}
4 & \\
\end{tabular} & 2 & 2 \\
\hline
\end{tabular}

Previous findings in psychology research showed that people's brains store information in a hieratical structure [6]. Therefore, by revealing the sequence and the times of drawing a specific element, people's cognitive processes can be traced. As is shown in the table above, the library catalogue and different forms of library resources were the ones that were relatively important when they were thinking of the conception "mobile library service".

Students engaged in the pilot study showed certain mobile information behaviour, and they made use of their mobile device as one of the important information source regarding their study needs. The frequently used library resources include the library catalogue, different types of electronic resources, databases and several library online services, such as "book status track" (a function that can check the availability, borrowing status and the location of the books). They also made use of the functions from their mobile devices to support their study (e.g: dictionary apps and notes taker apps).

The contexts and needs of using mobile devices to support learning process are diverse, which is mostly caused by their learning habits. Some students prefer to read articles on the train; some tend to write essays on their mobile phone while taking the bus. This explains the concept of "contextualization of learning" by using mobile devices that gives learners mobility to learn regardless of context and platform [16, p.2]. It also suggests that combining functions on the mobile phones and providing mobile access to library resources are necessary to meet users' information behaviour under different contexts and improve digital learning environment.

Another finding from the pilot study is about their expectations on the future library service development with mobile technologies, which encompass four aspects-functions, customisation and personalisation, design and data protection concerns. First of all, they pointed out the functions they wish to use specifically with mobile device, for example, library room booking, reliable checking of availability of library study spaces and the library catalogue. Secondly, they also conveyed a strong desire in having a personalized system which could give them unique recommendations for resources and updates, like reading lists and book recommendations. Thirdly, the design aspect of the mobile library service was mentioned as well with a focus on improving the usability of such service on mobile devices (e.g: visual representation). Finally, students engaged expressed their concerns on the data protection and ethical issues of using the library system on mobile devices. They hope to enjoy the convenience afforded by such technology, with their personal information being protected at the same time. This finding reveals the factors that may influence the user experience on mobile library service. As is illustrated by Beauregard and Corriveau in their conceptual framework of UX, the interaction between user and product is an iterative process, in which users' perception and intention of one product are influenced by their previous knowledge, concerns, skills and personalities [4]. The four aspects of the expectation found in the pilot study is in line with the influential factors in the UX framework.

From the pilot study, the cultural factors influencing information behaviour and UX with international Chinese students were explored. Two Chinese students engaged in the study expressed their cross-cultural perspectives as international students from a Confucian culture background. From their drawings and interviews, they both put emphasis on the friendly and straightforward design of the mobile library service (as one of them drew the desired interface of a mobile library, see section of his drawing in Figure 1). Avoiding jargon, they stressed the importance of a straightforward expression of the interface and techniques to improve accessibility. Hughes has found that rather than the linguistic factors, it is the cultural background and past learning experience that have more impact on international students' wider educational experience [15]. Thus, exploring the cultural influential factors on international students and improving the university services based on that is essential for the globalization strategy. This pilot study identifies the sample choice for the formal data collection, which will be focused on international Chinese students.

Through the pilot study, an initial view of the current UX on mobile library service was obtained. The research method, cognitive mapping, combined with semi-structured interview, was found to be a good way of helping participants deliberate on the research topic and of gathering abundant visual data in a relatively short time. 

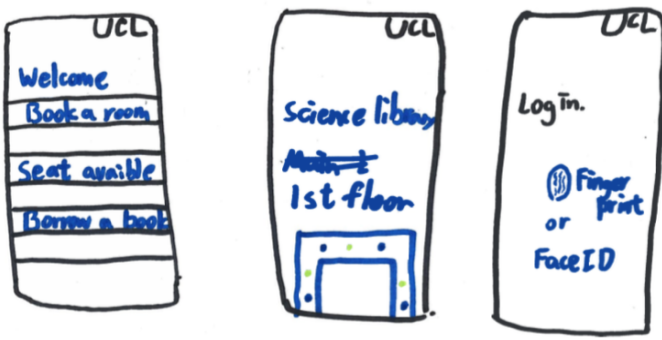

Figure 1: Part of the cognitive map by one Chinese student

\section{FUTURE PLAN}

The pilot study, as the first stage of research, tested the reliability and feasibility of the research methods and process design. The sample size and the specific user group for the formal data collection has been determined. A regional focus on international Chinese students studying in UK will be investigated. The rationale for this selection of sample is, on the one hand, two Chinese students engaged in the pilot study shared their UX with mobile technology from a specific cross-cultural viewpoint and this way of looking into UX has been overlooked; on the other hand, international Chinese student constitutes a considerable large number among the international students studying in UK [1], therefore learning their information behaviour and improving their experience studying abroad is of great value.

The next step of research is to analyse the backend data from the library of University College London. This part of data includes twelve months log data (October, 2017-October, 2018) from all students and it will show the behavioural characteristic of library users by the details of their user actions (what they did in the system), device usage (what devices and browsers used), facet usage, popular searches, sessions information (what country, where session took place) and other related information. Log analysis will be used to analyse this part of data. The finding on this stage will answer the RQ1 and guide the design of cognitive mapping and interview questions.

After finding out users' current behaviour, the last step is to explore the reasons behind this, and answer RQ2 and RQ3. This will be achieved by conducting cognitive mapping and interview sessions. Ultimately, a holistic view of users' information behaviour and UX on mobile library service with a specific cross-cultural perspective will be gained.

\section{ACKNOWLEDGMENTS}

This research is sponsored by China Scholarship Council (CSC)(File No.201808060180). The pilot study is supported and funded by UCL ChangeMakers (https://www.ucl.ac.uk/changemakers/). I would like to express my sincere gratitude to my $\mathrm{PhD}$ supervisors, Charlie Inskip and Elizabeth Lomas for their valuable support. Also, I want to give thanks to Margaret Stone (the Head of UCL Digital Libraries), Anne Binsfeld and Orla Delaney (my project team members) for their help on the project.

\section{REFERENCES}

[1] Higher Education Statistical Agency. 2018. Higher Education Student Statistics: UK, 2016/17. Retrieved December 9, 2018 from https://www.hesa.ac.uk/news/ 11-01-2018/sfr247-higher-education-student-statistics

[2] Noa Aharony. 2014. Mobile libraries: librarians' and students' perspectives. College \& Research Libraries 75, 2 (2014), 202-217.

[3] Andrew Asher and Susan Miller. 2011. So you want to do anthropology in your library. Or a practical guide to ethnographic research in academic libraries (2011).

[4] Russell Beauregard and Philip Corriveau. 2007. User experience quality: a conceptual framework for goal setting and measurement. In International Conference on Digital Human Modeling. Springer, 325-332.

[5] Steven J Bell. 2014. Staying true to the core: Designing the future academic library experience. portal: Libraries and the Academy 14, 3 (2014), 369-382.

[6] Sariya Binsaleh and Muazzan Binsaleh. 2013. Mobile learning: What guidelines should we produce in the context of mobile learning implementation in the conflict area of the four southernmost provinces of Thailand. Asian Social Science 9, 13 (2013), 270.

[7] Joanna Bryant, Graham Matthews, and Graham Walton. 2009. Academic libraries and social and learning space: A case study of Loughborough University Library, UK. Fournal of Librarianship and Information Science 41, 1 (2009), 7-18.

[8] Robin Canuel, Emily MacKenzie, Andrew Senior, and Nazi Torabi. 2017. Apps for academic success: Developing digital literacy and awareness to increase usage. Education for Information Preprint (2017), 1-18.

[9] Po-Sheng Chiu, Ying-Hung Pu, Tzung-Shi Chen, Yen-Hung Kuo, and Yueh-Min Huang. 2014. Design and development of a mobile library APP system. In Educational Innovation through Technology (EITT), 2014 International Conference of. IEEE, 43-48.

[10] Juliet Corbin, Anselm Strauss, et al. 2008. Basics of qualitative research: Techniques and procedures for developing grounded theory. (2008).

[11] Roger M Downs and David Stea. 1973. Cognitive maps and spatial behavior: Process and products. na.

[12] Lynda M Duke and Andrew D Asher. 2012. College libraries and student culture: What we now know. American Library Association.

[13] Raya Fidel. 2008. Are we there yet?: Mixed methods research in library and information science. Library \& Information Science Research 30, 4 (2008), 265272

[14] Jingru Hoivik. 2013. Global village: mobile access to library resources. Library Hi Tech 31, 3 (2013), 467-477.

[15] Hilary Hughes. 2005. Actions and reactions: exploring international students' use of online information resources. Australian Academic \& Research Libraries 36, 4 (2005), 169-179.

[16] JISC. 2011. Mobile learning-A practical guide for educational organisation planning to implement a mobile learning initiative. Retrieved December 9, 2018 from https://www.jisc.ac.uk/guides/mobile-learning

[17] Rob Kitchin, Scott Freundschuh, et al. 2000. Cognitive mapping: Past, present, and future. Vol. 4. Psychology press.

[18] Joan K Lippincott. 2010. A mobile future for academic libraries. Reference services review 38, 2 (2010), 205-213.

[19] Lynne EF McKechnie, Christopher M Dixon, Jana Fear, and Angela Pollak. 2013. Rules of (mis) conduct: User behaviour in public libraries. In Proceedings of the Annual Conference of CAIS/Actes du congrès annuel de l'ACSI.

[20] Donald A Norman. 2010. Living with complexity. MIT press.

[21] Lorraine Paterson and Boon Low. 2011. Student attitudes towards mobile library services for smartphones. Library Hi Tech 29, 3 (2011), 412-423.

[22] Andy Priestner and Matt Borg. 2016. User experience in libraries: applying ethnography and human-centred design. Routledge. 